\title{
Bathymetric maps from multi-temporal analysis of Sentinel-2 data: the case study of Limassol, Cyprus
}

\author{
Evagoras Evagorou, Christodoulos Mettas, Athos Agapiou, Kyriacos Themistocleous, and Diofantos Hadjimitsis \\ Department of Civil Engineering and Geomatics, School of Engineering and Technology, Cyprus University of Technology, \\ 30 Arch. Kyprianos Str., 3036 Limassol, Cyprus
}

Correspondence: Evagoras Evagorou (evagoras.evagorou@cut.ac.cy)

Received: 2 August 2018 - Revised: 15 December 2018 - Accepted: 23 December 2018 - Published: 9 January 2019

\begin{abstract}
During the last years, various methods and techniques have been used to estimate the seafloor topography with high accuracy. The topography is considered an important component for marine applications since several activities and infrastructures are being carried out at the bottom, column and surface of the sea. In this, study, freely and open distributed optical satellite images were used to obtain bathymetric data for shallow waters, (until $30 \mathrm{~m}$ below sea level) based on timeseries analysis of multispectral Sentinel2 datasets. The ratio transform algorithm was implemented for twelve (12) monthly images covering thus a whole year. The different generated Digital Terrain Models (DTMs) were compared with high resolution LIDAR measurements. The results showed that bathymetry can be obtained from satellite data within a Root Mean Square Error (RMSE) ranging from 1.39 up to $2.56 \mathrm{~m}$ while more accurate results were generated during the summer period.
\end{abstract}

\section{Introduction}

Bathymetrical data are a crucial component of the marine area since several activities and infrastructures are being carried out at bottom, column of the sea and sea surface. The importance of bathymetry is quite high in areas where there are shallow waters, such as harbors. Nowadays, various remote sensing datasets are used to determine the topography of the seafloor with high accuracy, including active sensors. Traditionally, the active sensors used for estimating bathymetry are the echo sounders (Multi-Beam Echo Sounders, Single-Beam Echo Sounders) or LIDAR devices installed on vessels following a course along specially designed sailing lines that have a specific geometry (Kearns and Breman, 2010). Beyond the fact that these methods are very accurate, they are also very time consuming and costly (McCaffrey, 1981; Sánchez-Carnero et al., 2012). Airborne LIDAR is another method that has been implemented for estimating the bathymetry which revealed to be cost effective compared onboard the vessels providing high area coverage faster (Irish and Lillycrop, 1999; Muirhead and Cracknell, 1986; Ogawa et al., 2017).

During the last years new studies related to SatelliteDerived Bathymetry (SDB) emphasize the potential use of optical satellite remote sensing sensors for bathymetric purposes. Indeed, analytical, semi-analytical and empirical approaches may be implemented for the estimation of bathymetry of up to $30 \mathrm{~m}$ depth. The analytical and semianalytical approaches are based on the physics of light's transmission in water using different parameters of the atmosphere, water column and bottom material. By comparing the three methods, the analytical and semi-analytical methods seem to be more complicated than the empirical one, with more parameters in order to extract bathymetrical data (Gao, 2009). Towards the end of 1970s, it was demonstrated that bathymetry could be estimated over clear shallow water using remote sensing with a multi-band log linear algorithm (Lyzenga, 1978, 1980). Afterwards, this analytical approach has been determined in various ways or with small modifications to derive bathymetry (Conger et al., 2006; Lyzenga et al., 2006; Maritorena et al., 1994; Philpot, 1989). An algorithm for determining the depth of penetration (DOP) zones for every band and calibrating depths presented by Jupp (1988). Also, semi-analytical approaches were implemented, using models and methods for retrieving bathymetry data (Adler-Golden et al., 2005; Lee et al., 1999). Systematic errors are experienced by using the analytical and 
semi-analytical approaches on the coastal areas containing seagrass because of the reflectance which is lower on the neighboring deep waters. This issue derives most probably from the shading which occurs within the canopy (Dekker et al., 2007). Another method was implemented, named ratio method, for the extraction of bathymetric data over clear shallow water (Stumpf et al., 2003), in which the authors argue that the ratio for two bands at the constant depth will be the same, independently of the difference of bottom albedo, and can be scaled with actual depths.

Over the years, many researches used several optical satellite imageries to extract bathymetrical data. As, remote sensing technologies are continuously upgrading, they are also expanding the horizons of researchers in the field of bathymetry using high resolution satellite images (Said et al., 2017; Setiawan et al., 2013). These multispectral sensors, provide a wide range of wavelength bands which can be applied to these models, especially green and blue bands which can penetrate up to $20 \mathrm{~m}$ underneath the sea surface in a clear water condition (Sutanto, 1992).

Despite the medium spatial resolution, open and freely distributed data have also attracted the interest of researchers. Indeed, during the years, different studies carried out to estimate bathymetry using freely distributed medium resolution (30 m pixel size) Landsat-7 ETM+ and Landsat8 LDCM satellites. The most common algorithms used in these studies where the log linear (Lyzenga, 1978, 1980) and the non-linear models (Stumpf et al., 2003). For instance the non-linear algorithm was applied to Landsat images in the area of the Dutch Wadden Sea (Ameland Inlet, Misra et al., 2018) with a coefficient of determination $\left(R^{2}\right)$ of 0.85 and Root-Mean-Square Error (RMSE) $3.12 \mathrm{~m}$; on Thousand island (Pushparaj and Hegde, 2017) with $R^{2}=0.90$ and $\mathrm{RMSE}=0.86 \mathrm{~m}$ for depths up to $10 \mathrm{~m}$ and at the coastal region of Dakshina Kanada in India, Kastela bay in the middle Adriatic with $R^{2}$ of 0.90 (Setiawan et al., 2017).

The exploitation of freely and open distributed datasets for bathymetric purposes has been supported by the new capabilities of the Sentinel-2 sensors, having a $10 \mathrm{~m}$ resolution. Recently, the log linear and non-linear methods were used for mapping the bathymetry, on the South Baltic Sea (Chybicki, 2017). In that study, satellite imageries from the Sentinel-2A sensor and soundings data were obtained by a single-beam echo sounder and were used to estimate SDB. Afterwards, error distribution and quality coefficient were calculated to describe the quality of the retrieved SDB. Further, the retrieved SDB was calibrated with the indicator of quality coefficient. In this way, more accurate results were retrieved from SDB, proposing the implementation of this indicator on mapping bathymetry using remote sensing. The best accuracy reported using the ratio transform algorithm method was with an $R^{2}=0.91$ and $\mathrm{RMSE}=1.08 \mathrm{~m}$. At the same time, Kabiri (2017) used linear, non-linear methods for bathymetric purposes on the Nayband bay, in Iran, using two Sentinel2 satellite imageries of February and March 2017. The best accuracy was estimated to 1.89 and $2.04 \mathrm{~m}$ for months February and March respectively, using the ratio transform algorithm.

More, recently the benefits of the Sentinel-2 imageries using big data cloud platforms were presented by Traganos et al. (2018). The Google Earth Engine, a cloud-based geospatial computing platform, was used to acquire Sentinel-2 imageries for the period between 1 August and 31 December 2016, in four different locations at the eastern Mediterranean basin. Analytical and empirical methods were implemented, including the pseudo-invariant features for normalisation and the median $3 \times 3$ filter to smooth the remaining noise, hence increasing SDB accuracies. The best accuracy spotted using the analytical method had a $R^{2}$ of 0.90 and $\mathrm{RMSE}=1.67 \mathrm{~m}$.

Though these studies have shown the great potentials of estimating bathymetry using freely and open source satellite data such as Sentinel-2 images, there is still a research to be performed regarding the identification of the best period throughout the year where bathymetric errors are minimized. In addition, bathymetric studies based on optical sensors are rare in the wider Eastern Mediterranean region and therefore extensive research will benefit in the future. Even though satellite remote sensing in this area was used in coastal areas for several purposes such as in marine spatial planning, monitoring archaeological sites, quality of coastal water etc. (Agapiou et al., 2011; Hadjimitsis et al., 2010, 2013; Papoutsa et al., 2011) no bathymetrical studies have been made. Currently through an existing funded project named as "THAL-CHOR 2" "“ $\Theta A \Lambda-X \Omega P$ 2" in Greek), bathymetric maps are being developed through the use of the remote sensing which will be used for the implementation of marine spatial planning in Cyprus.

For the framework of this study, optical Sentinel-2 satellite data were used to extract bathymetric information in Cyprus. The present study is comprised of five parts. Further to the introduction, the datasets and methodology part follows, mentioning the field data of Multi-Beam Echo Sounders and LIDAR instruments. Then, the empirical approach and the methodology used in this study is described. The next part concentrates the results of the applied methodology providing the correlation between observed depths and SDB depths, twelve bathymetric maps. Finally, the paper ends with a discussion and the conclusions.

\section{Case study and datasets}

\subsection{Study site}

The study site is located south west of the city of Limassol in Cyprus and it covers $19 \mathrm{~km}^{2}$ with a coastline that is about $9.6 \mathrm{~km}$ in length (Fig. 1). The site is located between $34^{\circ} 41^{\prime} 38.4^{\prime \prime}-34^{\circ} 42^{\prime} 7.2^{\prime \prime} \mathrm{S}$ and $33^{\circ} 4^{\prime} 30^{\prime \prime}$ $33^{\circ} 10^{\prime} 44.4^{\prime \prime} \mathrm{E}$ (WGS $84,36 \mathrm{~N}$ ). On the coastlines of the study 


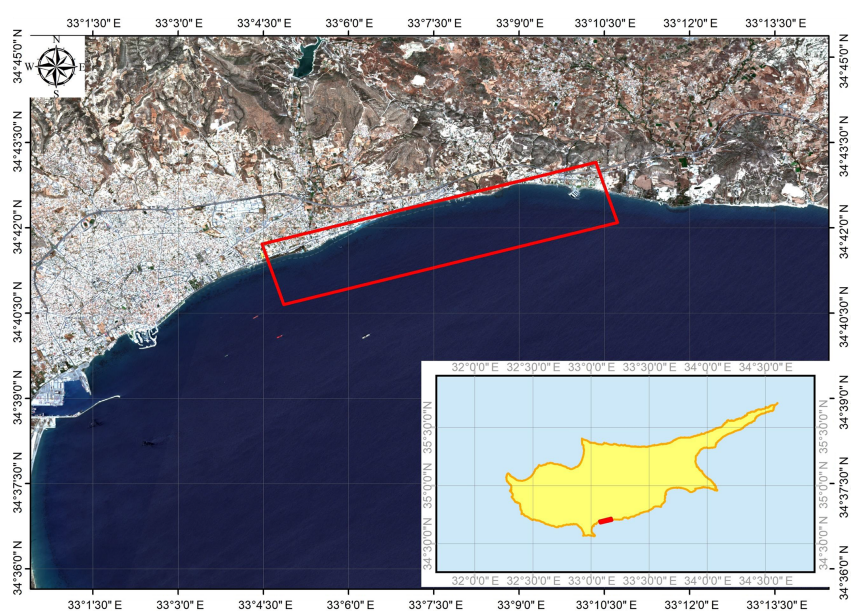

Figure 1. Location of study site in Cyprus.

area, the soft substrate with sandy beaches from shallow waters to a depth of twenty meters is gradually becoming muddy (DoF, 2012). Also, breakwaters can be found on the coasts of Limassol at a distance of $120 \mathrm{~m}$ from the shoreline. Cyprus has an intense Mediterranean climate with hot dry summers, rainy, rather changeable, winters and in autumn and spring season the weather conditions are changing rapidly. The winds usually are light to moderate and rarely unstable.

\subsection{Sentinel-2 optical satellite data}

In this study, Sentinel-2 imagery and field data were used to analyse and estimate bathymetry. Sentinel-2 mission is part of the European Space Agency (ESA) with high-resolution with multi-spectral imagery. The current research aims to compare the estimated results of bathymetry for each month separately. Therefore twelve processed satellite images (one for each month) were acquired through the Copernicus minor site (ESA, 2013), covering a period from April 2017 to March 2018. Table 1 shows the details of acquired satellite image that were used. The acquired packages are of Level 2A i.e. orthoimages and bottom of atmosphere corrected reflectance product. At this stage, the product was processed on radiometric, geometric, cloud screening and atmospheric corrections. These multispectral images have 12 bands of spectral range at three different resolutions (bands/resolution: b1 - Coastal aerosol/60 m , b2 - Blue/10 m, b3 - Green/10 m, b4 - Red/10 m, b5 - Vegetation Red Edge/20 m, b6 - Vegetation Red Edge/20 m, b7 - Vegetation Red Edge/20 m, b8 - NIR/10 m, b8A - Vegetation Red Edge/20 m, b9 - Water vapour/60 m, b10 - SWIR/60 m, b11 - SWIR/60 m, b12 - SWIR/60 m).

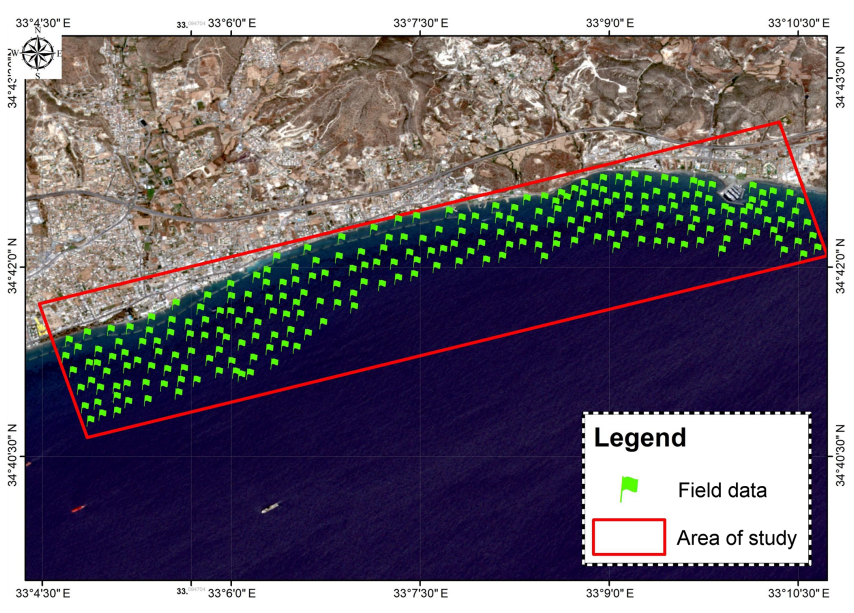

Figure 2. Field data acquired by the Department of Land Survey in Cyprus.

\subsection{LIDAR in-situ data}

The in-situ data were collected and analyzed by the Department of Land Surveyors of Cyprus (DLS, 2014) - the official chartographic provider of the country - covering water depths up to $50 \mathrm{~m}$ for an area of approximately $508 \mathrm{~km}^{2}$. The data were acquired in two phases; the first phase was conducted in 2012 when the DLS launched process mapping of the sea with multi-beam echo sounders using a conventional vessel covering $238 \mathrm{~km}^{2}$; the second phase was conducted in 2014 using the airborne LIDAR method covering $270 \mathrm{~km}^{2}$. The vertical accuracy as estimated by the DLS is $\pm 0.5 \mathrm{~m}$ for depths 0 to $20 \mathrm{~m}$ and $\pm 1 \mathrm{~m}$ for up to $50 \mathrm{~m}$. Consequently, for this research, the DLS provided a set of 244 random control points of 0 to $22 \mathrm{~m}$ depth which have been used for: (a) calibrating the bathymetric results obtain from the multispectral imageries to absolute depths and (b) for training the ratio transform algorithm. Figure 2, shows the overall geographical distribution of the control points within the area of interest.

\section{Methodology}

Several methods have been implemented for the estimation of the bathymetry using remote sensing. This research, gives emphasis in one of the most commonly used methods (ratio transform algorithm) for deriving depths using satellite imagery, (Stumpf et al., 2003). In this method, the approach of Beer's Law was accepted which considers that light attenuation in the water column increases exponentially as depth increases (Gao, 2009). The log transformation algorithm is related to the natural logarithm for reflectance of two bands and actual depths.

Therefore, the bands used for estimating the bathymetry are the blue $(440-540 \mathrm{~nm})$, green $(500-600 \mathrm{~nm})$, red (600$700 \mathrm{~nm})$ and near infrared $(700-800 \mathrm{~nm})$ bands. The pene- 
Table 1. Details for the processed Sentinel-2 imageries.

\begin{tabular}{llrrrr}
\hline A/A & Name & $\begin{array}{r}\text { Date } \\
\text { Acquisition }\end{array}$ & $\begin{array}{r}\text { Sensing } \\
\text { Time }\end{array}$ & $\begin{array}{r}\text { Sun Zenith } \\
\text { Angle }\left({ }^{\circ}\right)\end{array}$ & $\begin{array}{r}\text { Sun Azimuth } \\
\text { Angle }\left(^{\circ}\right)\end{array}$ \\
Coverage $(\%)$
\end{tabular}

tration in the blue and green part of the spectrum is higher while the absorption of the electromagnetic radiation is increasing as we move to the red part of the spectrum. The ratio transform algorithm can be apply with bands having different water absorption and can be applied in appropriate wavelengths of any sensor. Since blue and green bands have lower absorption, their ratio should remain the same despite the different bottom albedos at a constant depth. The values of these bands were implemented on the following Eq. (1) to estimate bathymetry.

$Z=m 1 \frac{\ln R(\lambda b)}{\ln R(\lambda g)}-m 0$

where $Z$ is the satellite derived bathymetry depth, $m 0$ is the offset for a depth of $0 \mathrm{~m}, m 1$ is a coefficient to tune the model to the actual depth, and $R(\lambda b)$ and $R(\lambda j)$ are the remote sensing radiances for optical bands $\lambda b$ (blue band) and $\lambda g$ (green). For this model, the bottom depth is estimated on the basis of light attenuation phenomena, as the attenuation of the incoming shortwave radiation varies spectrally.

The ratio transform algorithm was implemented to the multispectral imageries listed in Table 1. Initially the multispectral images were resampled by a referenced band with a $10 \mathrm{~m}$ spatial resolution, using the SNAP software. Upon the selection of the area of interest, the ArcGIS software was used where the shapefile was created and uploaded on the SNAP software to mask satellite imageries. Following, each one of the masked imageries classified the blue, green, red and near infrared band and then separated land and water. After the pre-processing of satellite data, the processed product was uploaded on the ENVI 5.3 software for estimating the bathymetry using the log transformation algorithm. The median filter, a nonlinear digital filtering technique, used for removing the noise from images, was applied to this study. A median filter of $7 \times 7$ was used to succeed the reduction of the noise of high frequency. The following figure (Fig. 3), shows the processing steps for deriving bathymetry on the study area.

\section{Results}

Following the above methodology, twelve bathymetry maps, one for each month, were estimated. The median filter has been implemented to eliminate parameters of deterioration in estimating bathymetry such as turbidity, waves, sun glint and sky glint. Following a time series regression analyses, the RMSE and Mean Absolute Errors (MAE) have been calculated.

\subsection{Time series regression analyses of Bathymetrical data}

In order to estimate the correspondence of the satellite bathymetric model with the Lidar datasets a regression analysis has been performed for each monthly DTM using the linear model. The overall results are found in Fig. 4. Twelve scatterplots have been designed with the $x$-axis representing the LIDAR points, while the $y$-axis represented the estimated bathymetry points derived from the Sentinel- 2 images. Based on the linear regression analysis the $R^{2}$ coefficient was also estimated for each case. According to the results, strong correlation is observed in shallow waters (less than $12 \mathrm{~m}$ ) compared to deeper areas (more than $12 \mathrm{~m}$ ). Scatterplots of January and February show that $R^{2}$ is relatively high up to 0.90 while $R^{2}$ for the next couple of months is estimated to be between 0.85 and 0.88 . During summer season $R^{2}$ value is increased while June provides the best linear fit with a value of 0.95 . Lastly, the $R^{2}$ value for autumn, seems to have a downward trend and is the same with winter's one. The scattering starts from $12 \mathrm{~m}$ depth, as also clearly showed for the analysis during November. This is reflected to the $R^{2}$ value which is equal to the 0.81 and it is the less precise value from the results.

In order to compare the accuracy of the time series extracted results, two statistical parameters were taken into consideration along with correlation coefficient $R^{2}$, RMSE and MAE. The equations for the estimation are given in the 


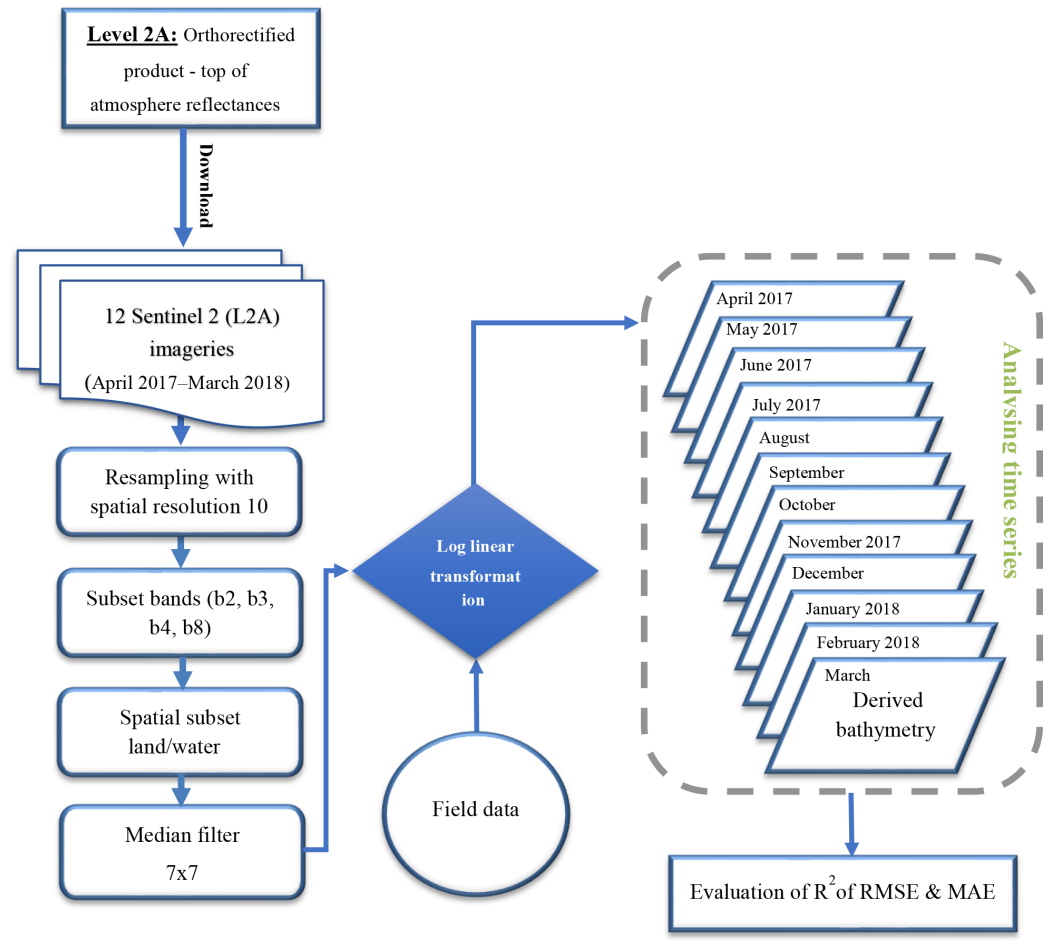

Figure 3. Workflow processing steps detecting bathymetry from Sentinel-2 (L2A) satellites images.

following equations:

$$
\begin{aligned}
& \mathrm{RMSE}=\frac{1}{n} \sum_{J=1}^{1}\left|Z_{\mathrm{SDB}}-Z_{\mathrm{FB}}\right| \\
& \mathrm{MAE}=\sqrt{\frac{1}{n} \sum_{J=1}^{1}\left(Z_{\mathrm{SDB}}-Z_{\mathrm{FB}}\right)^{2}}
\end{aligned}
$$

where $n$ is the number the field points, $Z_{\mathrm{SDB}}$ is the satellite derived bathymetry depth and $Z_{\mathrm{FB}}$ is the field points depth.

The overall results regarding the RMSE and MAE errors are shown on Table 2. As resulted from the table below, the best results were the ones derived for month June where the bathymetry resulted with RMSE to be $1.39 \mathrm{~m}$ and MAE $1.05 \mathrm{~m}$. On the other hand, the less precise results having a RMSE of $2.56 \mathrm{~m}$ and a MAE of $1.64 \mathrm{~m}$ seem to be for month November.

\subsection{Results of bathymetrical data}

This section demonstrates and compares the various SDB maps produced from the Sentinel-2 images with the LIDAR datasets. Figure 5 below, shows the bathymetrical results of the study area for each month. Overall, the best accuracy is evident during the summer period with RMSE of $1.39 \mathrm{~m}$ and MAE of $1.05 \mathrm{~m}$ while the autumn period gives the lowest precision with RMSE of $2.56 \mathrm{~m}$ and MAE of $1.64 \mathrm{~m}$. The latest may be due to bad weather conditions and the sea state. It is worth noted that bathymetric maps obtained during the
Table 2. $R^{2}$, RMSE and MAE of the estimated depths.

\begin{tabular}{lrrr}
\hline Period & $R^{2}$ & $\begin{array}{r}\text { Root-mean-square } \\
\text { error (RMSE) } \mathrm{m}\end{array}$ & $\begin{array}{r}\text { Mean absolute } \\
\text { error (MAE) m }\end{array}$ \\
\hline January & 0.90 & 1.91 & 1.30 \\
February & 0.90 & 1.90 & 1.33 \\
March & 0.88 & 2.01 & 1.33 \\
April & 0.85 & 2.35 & 1.37 \\
May & 0.91 & 1.70 & 1.37 \\
June & 0.95 & 1.39 & 1.05 \\
July & 0.92 & 1.64 & 1.32 \\
August & 0.94 & 1.43 & 1.09 \\
September & 0.87 & 2.07 & 1.66 \\
October & 0.85 & 2.46 & 1.61 \\
November & 0.81 & 2.56 & 1.64 \\
December & 0.90 & 1.86 & 1.19 \\
\hline
\end{tabular}

period November December encountered error in the SouthEast. These errors are probably related to cloud coverage of the satellite images.

As it can be seen from the presentation of the results, the period used for estimating bathymetry effects the overall performance of the results. The records provided by the DLS have a 5-year difference from the downloading of the satellite images which is considered to be a very long timeframe, thus data have limitations on the accuracy. In order to compare the estimated bathymetry with the in situ data, comparison maps 


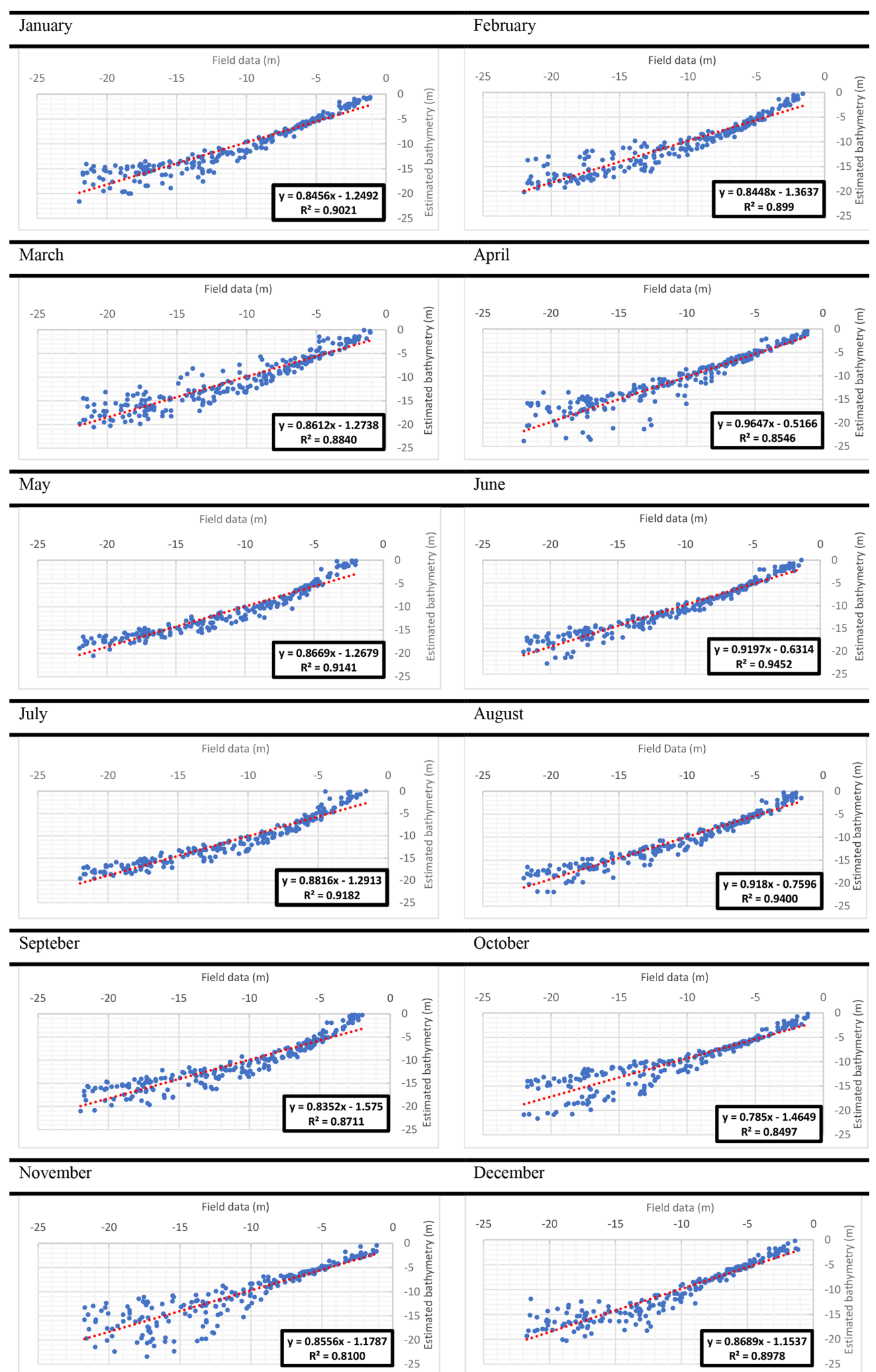

Figure 4. Correlation between observed depths and SDB depths obtained for each month. 

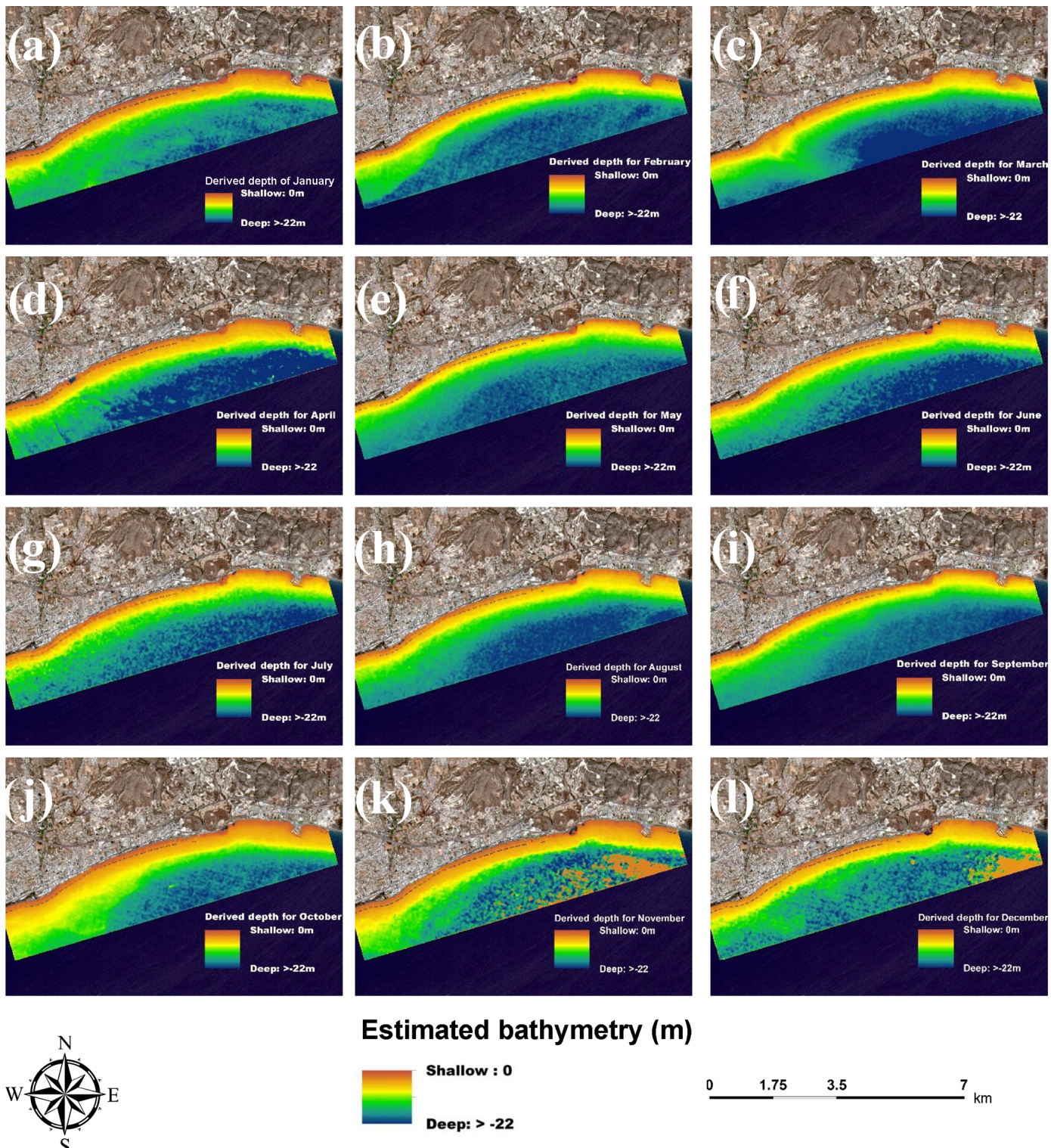

Estimated bathymetry $(\mathrm{m})$
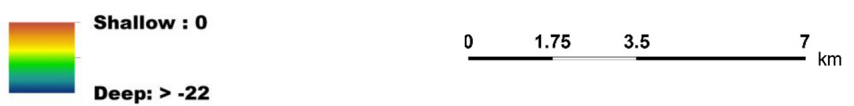

Figure 5. Predicting and mapping SDB with ranges 0 to $-22 \mathrm{~m}$ depth, for the months (a) January, (b) February, (c) March, (d) April, (e) May, (f) June, (g) July, (h) August, (i) September, (j) October, (k) November, (l) December.

between the bathymetric satellite DTMs and LIDAR DTMs were created and can been seen on Fig. 6 .

Based on these findings it is evident that during winter and autumn periods errors can be more than $5 \mathrm{~m}$. Higher errors of more than $4 \mathrm{~m}$ are reported in deeper waters for all seasons with the exception of the summer season. In shallow waters the same performance despite the period selected was observed. In addition, in sea areas with breakwaters the differences range from 1 up to $2.5 \mathrm{~m}$.

Bathymetrical profiles were also created in areas that showed frequently encountered errors. Optically observing the maps with the errors' allocation, it can be pointed out that there are more frequent errors in the southwest of the study area. Bathymetrical profile lines of each month were used in order to interpolate the bathymetrical data. Besides, another profile was created, which is based on the LIDAR control points in order to be compared with those of SDB. The above described method was followed with the use of ArcGIS v10.2 Software for the analysis of the diagrams which have been exported by the software, the user has resulted to the diagram depicted in Fig. 7

A very good correlation between the profiles is perceptible to Fig. 7. For a horizontal distance from the coastline up to $200 \mathrm{~m}$ with depths of $5 \mathrm{~m}$, a noise was observed between SDB and the interpolated bathymetry from the field points. This might be due to the wave collapse on the shore- 

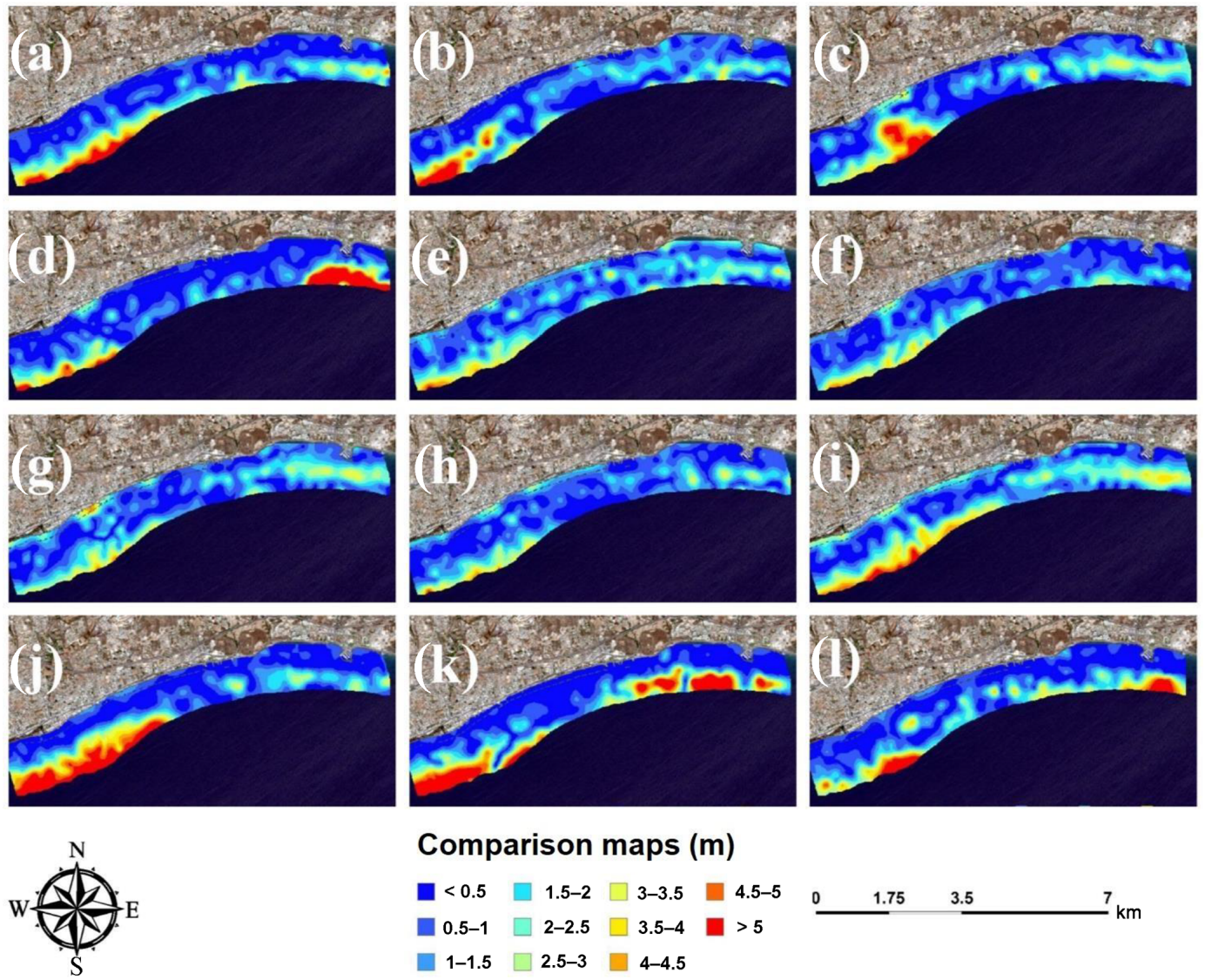

Figure 6. Comparison maps of the estimated bathymetry and in situ data for the months: (a) January, (b) February, (c) March, (d) April, (e) May, (f) June, (g) July, (h) August, (i) September, (j) October, (k) November , (l) December.

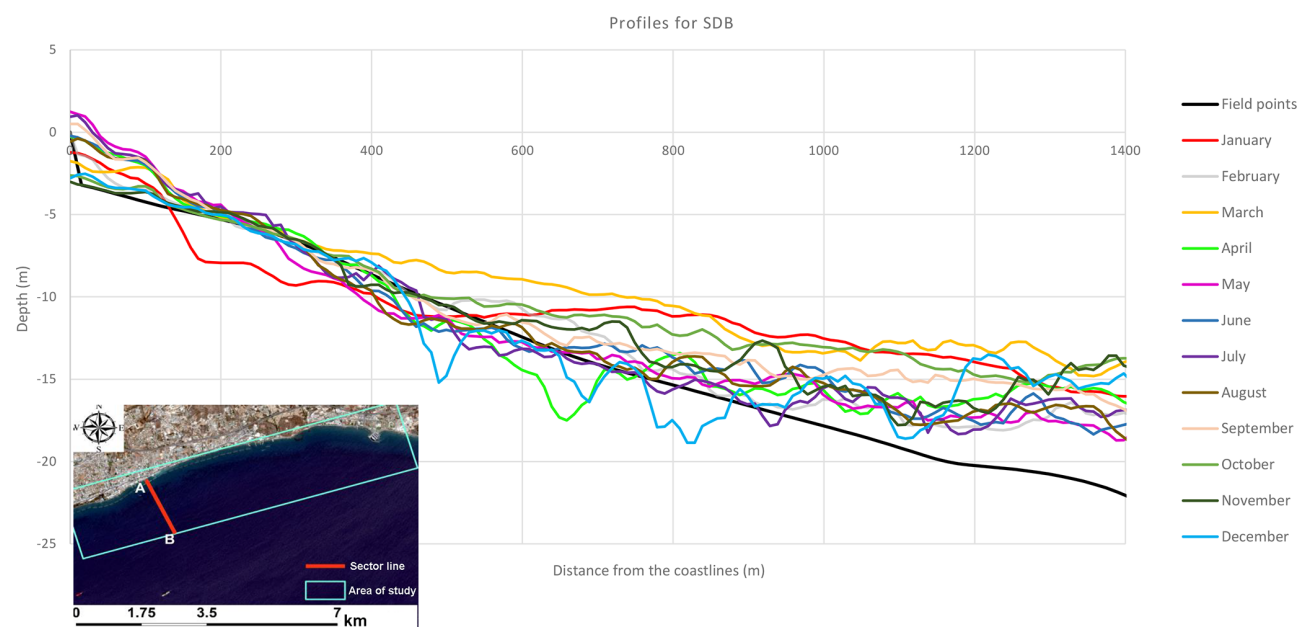

Figure 7. Sector profiles of SDB.

line and the breakwaters which are located $120 \mathrm{~m}$ from the shoreline. On the other hand, on the coastal distance of 200 to $400 \mathrm{~m}$ in the area with depth of 5-10 $\mathrm{m}$ seems to be well correlated except the month of January. Moreover, the correlation of the bathymetric data with distance ranging from 400
$800 \mathrm{~m}$ seems to be good except from the months of March, April and December. Lastly, the distance ranging from 800 $1200 \mathrm{~m}$ with $20 \mathrm{~m}$ depth has a gradual upward shift of from the fields' points' surface. This might be due to the attenuation of the light as it passes through the water column and the 
deterioration of solar radiation at various depths in the water. Another reason could be the time difference between satellite images and field points.

\section{Discussion}

On the current study, twelve images, one for each month, have been used for estimating the bathymetry in the south area of Cyprus. During the analysis, the overall results indicate an error ranging from 1.39 up to $2.56 \mathrm{~m}$. Comparing the bathymetric data, it is evident, summer months provide the best results. Indeed, the best accuracy of bathymetry data is found in Sentinel image acquired on June with a $R^{2}=0.94$, $\mathrm{RMSE}=1.39 \mathrm{~m}$ and $\mathrm{MAE}=1.05 \mathrm{~m}$. Also, a good correlation between the bathymetric maps of May's to Augusts' (Fig. 5) with accuracies of the RMSE ranging from 1.39 to $1.70 \mathrm{~m}$ was observed. In contrast errors of more than $5 \mathrm{~m}$ during the autumn and winter months, especially in October and November have been reported in deeper waters. The accuracy of the study is considered acceptable, compared to other studies using the same method and satellite imageries such as those of Chybicki (2017), Kabiri (2017) and Traganos and Reinartz (2017). The correlation between situ data and predicted depths, is not the ideal and this may be due the limitations of accuracy that have LIDAR data. Also, a gradual increase in the accuracy of the results was noted in the months of June and December, months of the winter and summer solstice.

An overall analysis indicates high accuracy of the estimated depths in shallow waters which then reduces in deeper waters. Studying the bathymetrical profiles shows a good correlation between the observed and extracted depths from 5 to $12 \mathrm{~m}$ while there were deviations in deep waters. The correlation between the in situ data and results can be found in other studies that show better results in shallow waters (Ehses and Rooney, 2015; Pushparaj and Hegde, 2017).

Further to this study, comparison maps were created. The outcome of the maps shows the difference between the estimated bathymetry with the in-situ data. These comparison maps show good correlation to the shallow waters, with the differences ranging from 0.5 to $1.5 \mathrm{~m}$. It is also worth to notice that breakwaters in the study area might have deteriorated the results as shown in the comparison maps.

\section{Conclusions}

Bathymetry is an important factor for several applications such as navigation, marine environmental protection, coastal engineering etc. During the last years many studies implemented SDB using empirical, analytical and semi-analytical approaches, aiming to investigate the potential use of optical satellite datasets. A critical aspect highlighted on most of these studies refers to the atmospheric and sea conditions of the area including water column and bottom material charac- teristics. It is therefore important to analyse an optical satellite image with the best possible conditions (cloud coverage, waves, turbidity etc.). For this reason, the study was focused to the identification of the best period for the estimation of the bathymetry following a multi-temporal approach.

Therefore, the study was focused on the analysis of the multi-temporal Sentinel-2 satellite imageries in different periods using the empirical method ratio transform algorithm. The bathymetrical data were extracted using SDB and statistically analyzed for one year. The overall results show that the bathymetry accuracy tends to fluctuate from period to period significantly and therefore this should be taken into consideration in combination with the weather conditions. The latest is due to the fact that turbidity and waves affect the attenuation of the light observed during bad weather conditions and strong winds.

For the purpose of improving the current study, a comparison timeseries analysis exploiting ESA's Sentinel Scientific Data hub will be performed in the near future. Based on the given high temporal resolution of Sentinel-L2A-B sensors, a multitemporal analysis during the summer season (optimum period for bathymetric purposes as evidence in this paper) will be investigated by authors in the near future. The purpose of that study is to identify fluctuations within a specific season (i.e. summer), following other methods as well, aiming to minimize even more the errors and produce more accurate bathymetric maps. In addition, this will allow isolate the optimum window for exploiting the free and open satellite data.

Data availability. The original field data presented in the paper are available by contacting the Department of Land Surveyors of Cyprus. The original data underlying the satellite imageries are available in the Copernicus minor site.

Author contributions. EE, designed the entire project, wrote the main content and analyzed the data. CM, AA, KT and DH worked for the structure, proofreading and commenting of this paper.

Competing interests. The authors declare that they have no conflict of interest.

Special issue statement. This article is part of the special issue "Earth surveillance and space-based monitoring of the environment: integrated approaches". It is a result of the EGU General Assembly 2018, Vienna, Austria, 8-13 April 2018.

Acknowledgements. This research was supported by project entitled: "Cross-Border Cooperation for Implementation of Maritime Spatial Planning" referred as "THAL-CHOR 2" (" $\Theta \mathrm{A} \Lambda-\mathrm{X} \Omega \mathrm{P} 2$ " in Greek) and is co-funded by the European Regional Development 
Fund (ERDF), under the Cross-Border Cooperation Programme "INTERREG V-A Greece-Cyprus 2014-2020". Thanks, are given to the Remote Sensing and Geo-Environment Lab, of the Cyprus University of Technology. Also, acknowledgements are given to Department of the Land Survey of Cyprus, for providing soundings of bathymetry. Sentinel-2A imagery was acquired for the ESA's Sentinel Scientific Data hub.

Edited by: Silas Michaelides

Reviewed by: three anonymous referees

\section{References}

Adler-Golden, S. M., Acharya, P. K., Berk, A., Matthew, M. W., and Gorodetzky, D.: Remote bathymetry of the littoral zone from AVIRIS, LASH, and QuickBird imagery, Trans. Geosci. Remote Sens., 43, 337-347, https://doi.org/10.1109/TGRS.2004.841246, 2005.

Agapiou, A., Hadjimitsis, D. G., Papoutsa, C., Alexakis, D. D., and Papadavid, G.: The Importance of Accounting for Atmospheric Effects in the Application of NDVI and Interpretation of Satellite Imagery Supporting Archaeological Research: The Case Studies of Palaepaphos and Nea Paphos Sites in Cyprus, Remote Sens., 3, 2605-2629, https://doi.org/10.3390/rs3122605, 2011.

Chybicki, A.: Mapping South Baltic Near-Shore Bathymetry Using Sentinel-2 Observations, Polish Marit. Res., 24, 15-25, https://doi.org/10.1515/pomr-2017-0086, 2017.

Conger, C. L., Hochberg, E. J., Fletcher, C. H., and Atkinson, M. J.: Decorrelating remote sensing color bands from bathymetry in optically shallow waters, IEEE T. Geosci. Remote, 44, 16551660, https://doi.org/10.1109/TGRS.2006.870405, 2006.

Dekker, A., Brando, V., Anstee, J., Fyfe, S., Malthus, T., and Karpouzli, E.: Remote Sensing of Seagrass Ecosystems: Use of Spaceborne and Airborne Sensors, in Seagrasses: Biology, Ecology and Conservation, pp. 347-359, Springer Netherlands, Dordrecht, 2007.

DLS: Data from Department of Land Surveyors, Dep. L. Surv., available at: http://portal.dls.moi.gov.cy/en-us/Pages/ The-Department-of-Lands-and-Surveys-Web-Portal.aspx (last access: 17 May 2018), 2014.

DoF: Department of Fisheries and Marine Research: Initial Assessment of the Marine Environment of Cyprus, Part I - Characteristics Nicosia, Nicosia, 2012.

Ehses, J. S. and Rooney, J. J.: Depth Derivation Using Multispectral WorldView-2 Satellite Imagery, NOAA Tech. Memo. NMFSPIFSC-46, (June), 24, https://doi.org/10.7289/V5668B40, 2015.

ESA: SENTINEL-2 User Handbook, 1st Edm., available at: https://earth.esa.int/documents/247904/685211/Sentinel-2_ User_Handbook (last access: 24 July 2018), 2013.

Gao, J.: Bathymetric mapping by means of remote sensing: methods, accuracy and limitations, Prog. Phys. Geogr., 33, 103-116, https://doi.org/10.1177/0309133309105657, 2009.

Hadjimitsis, D., Agapiou, A., Alexakis, D., and Sarris, A.: Exploring natural and anthropogenic risk for cultural heritage in Cyprus using remote sensing and GIS, Int. J. Digit. Earth, 6, 115-142, https://doi.org/10.1080/17538947.2011.602119, 2013.

Hadjimitsis, D. G., Hadjimitsis, M. G., Toulios, L., and Clayton, C.: Use of space technology for assisting water quality assessment and monitoring of inland water bodies, Phys. Chem. Earth, 35, 115-120, https://doi.org/10.1016/J.PCE.2010.03.033, 2010.

Irish, J. L. and Lillycrop, W. J.: Scanning laser mapping of the coastal zone: the SHOALS system, ISPRS J. Photogramm. Remote Sens., 54, 123-129, https://doi.org/10.1016/S09242716(99)00003-9, 1999.

Jupp, D.: Background and Extensions to Depth of Penetration (DOP) Mapping in Shallow Coastal Waters, Proceeding Symp. Remote Sens. Coast. Zo. Queensl., available at: https://ci.nii.ac. jp/naid/10003995403/ (last access: 5 December 2018), 1988.

Kabiri, K.: Discovering optimum method to extract depth information for nearshore coastal waters from sentinel2a imagery-case study: nayband bay, iran, ISPRS - Int. Arch. Photogramm. Remote Sens. Spat. Inf. Sci., XLII4/W4, 105-110, https://doi.org/10.5194/isprs-archives-XLII-4W4-105-2017, 2017.

Kearns, T. A. and Breman, J.: Bathymetry-the art and science of seafloor modeling for modern applications, in: Ocean globe, 137, available at: http://visualsoundings.org/wp-content/uploads/ 2017/02/ocean_globe.pdf (last access: 6 December 2018), 2010.

Lee, Z., Carder, K. L., Mobley, C. D., Steward, R. G., and Patch, J. S.: Hyperspectral remote sensing for shallow waters: 2. Deriving bottom depths and water properties by optimization, available at: https://www.osapublishing.org/ao/abstract.cfm?uri= ao-38-18-3831 (last access: 4 December 2018), 1999.

Lyzenga, D.: Remote sensing of bottom reflectance and water attenuation parameters in shallow water using aircraft and Landsat data Remote sensing of bottom reflectance and water attenuation parameters in shallow water using air, Int. J. Remote Sens., 2, 71-82, https://doi.org/10.1080/01431168108948342, 1980.

Lyzenga, D. R.: Passive remote sensing techniques for mapping water depth and bottom features, Appl. Opt., 17, 379-383, https://doi.org/10.1364/AO.17.000379, 1978.

Lyzenga, D. R., Malinas, N. P., and Tanis, F. J.: Multispectral bathymetry using a simple physically based algorithm, IEEE T. Geosci. Remote, 44, 2251-2259, https://doi.org/10.1109/TGRS.2006.872909, 2006.

Maritorena, S., Morel, A., and Gentili, B.: Diffuse reflectance of oceanic shallow waters: Influence of water depth and bottom albedo, Limnol. Oceanogr., 39, 1689-1703, https://doi.org/10.4319/lo.1994.39.7.1689, 1994.

McCaffrey, E.: A review of the bathymetric swath survey system, International Hydrographic Bureau, available at: https:// journals.lib.unb.ca/index.php/ihr/article/view/23587/27360 (last access: 24 July 2018), 1981.

Misra, A., Vojinovic, Z., Ramakrishnan, B., Luijendijk, A., and Ranasinghe, R.: Shallow water bathymetry mapping using Support Vector Machine (SVM) technique and multispectral imagery, Int. J. Remote Sens., 39, 4431-4450, https://doi.org/10.1080/01431161.2017.1421796, 2018.

Muirhead, K. and Cracknell, A. P.: Airborne lidar bathymetry, Int. J. Remote Sens., 7, 597-614, https://doi.org/10.1080/01431168608954714, 1986.

Ogawa, H., Oyakawa, K., Kawai, K., Ozawa, H., Yajima, H., Shirane, H., Yamano, H., Hirata, N., Iwamoto, N., Ono, T., Tomizawa, S., Matsumoto, Y. and Yamakawa, S.: Airborne lidar bathymetry, International Hydrographic Bureau, available at: https://journals.lib.unb.ca/index.php/ihr/ 
article/view/26300/1882519053 (last access: 24 July 2018), 2017.

Papoutsa, C., Hadjimitsis, D. G., and Alexakis, D. D.: Coastal water quality near to desalination project in Cyprus using Earth observation, International Society for Optics and Photonics 8181, Earth Resources and Environmental Remote Sensing/GIS Applications II, p. 81810T, https://doi.org/10.1117/12.898361, 2011.

Philpot, W. D.: Bathymetric mapping with passive multispectral imagery, Appl. Opt., 28, 1569-1578, https://doi.org/10.1364/AO.28.001569, 1989.

Pushparaj, J. and Hegde, A. V.: Estimation of bathymetry along the coast of Mangaluru using Landsat-8 imagery, Int. J. Ocean Clim. Syst., 8, 71-83, https://doi.org/10.1177/1759313116679672, 2017.

Said, N. M., Mahmud, R., and Hasan, R. C.: Satellite-derived bathymetry: accuracy assessment on depths derivation algorithm for shallow water area, ISPRS - Int. Arch. Photogramm. Remote Sens. Spat. Inf. Sci., XLII-4/W5, 159-164, https://doi.org/10.5194/isprs-archives-XLII-4-W5-159-2017, 2017.

Sánchez-Carnero, N., Aceña, S., Rodríguez-Pérez, D., Couñago, E., Fraile, P., and Freire, J.: Fast and low-cost method for VBES bathymetry generation in coastal areas, Estuar. Coast. Shelf Sci., 114, 175-182, https://doi.org/10.1016/J.ECSS.2012.08.018, 2012.
Setiawan, I. E., Yuwono, D. M., Siregar, V. P., and Pramono, G. H.: The Study of Sea Bottom Morphology and Bathymetric Mapping Using Worldview-2 Imagery, in: Seminar Proceeding, 143-149, available at: https://repository.ipb.ac.id/jspui/bitstream/123456789/65453/1/ Iwan E. Setiawan \%2C vincentius siregar.pdf, 2013.

Setiawan, K. T., Adawiah, S. W., Marini, Y., and Winarso, G.: Bathymetry Data Extraction Analysis Using Landsat 8 Data, Int. J. Remote Sens. Earth Sci., 13, 79-86, https://doi.org/10.30536/j.ijreses.2016.v13.a2448, 2017.

Stumpf, R. P., Holderied, K., and Sinclair, M.: Determination of water depth with high-resolution satellite imagery over variable bottom types, Limnol. Oceanogr., 48, 547-556, https://doi.org/10.4319/lo.2003.48.1_part_2.0547, 2003.

Sutanto: Penginderaan Jauh Jilid 2, Gadjah Mada Press, Yogyakarta, 1992.

Traganos, D. and Reinartz, P.: Mapping Mediterranean seagrasses with Sentinel-2 imagery, Mar. Pollut. Bull., 134, 197-209, https://doi.org/10.1016/j.marpolbul.2017.06.075, 2017.

Traganos, D., Poursanidis, D., Aggarwal, B., Chrysoulakis, N., and Reinartz, P.: Estimating Satellite-Derived Bathymetry (SDB) with the Google Earth Engine and Sentinel-2, Remote Sens., 10, 859, https://doi.org/10.3390/rs10060859, 2018. 